\title{
Editorial
}

\section{Beverages: A Requirement for Life and an Opportunity to Impact the Way We Live It}

\section{Edgar Chambers IV}

Sensory Analysis Center, Department of Human Nutrition, Kansas State University, Manhattan, KS 66506-1407, USA; E-Mail: eciv@ksu.edu; Tel.: +1-785-532-0156

Received: 17 May 2014 / Accepted: 20 May 2014 / Published: 26 May 2014

Imagine a product that is used everyday by everyone around the world. In fact, imagine a product that must be used multiple times a day by everyone. That product is a beverage. Without beverages we cannot live. Many health practitioners recommend that adults consume approximately 2 liters of liquid daily and most of that consumption comes from beverages. Those beverages range from water to alcoholic beverages, soft drinks to coffee, tea to juice, and milk to so-called energy drinks or functional beverages. This enormous variety and consumption of beverages provides an unlimited opportunity to study product development and manufacturing, human consumption behavior, physical health and happiness, sensory impacts, public policy and a host of other important topics.

Major changes in beverage consumption have occurred in all parts of the world. Recently, bottled water overtook soft drink consumption in the U.S. but soft drink consumption in many other parts of the world is increasing. Modifications to alcohol consumption patterns are ongoing and increases in sales of specialty coffee and tea are found around the globe. Changes in climate result in changes in the need for liquids and also in the types of beverages consumed. Similarly, increases in per capita income in many countries result in the purchase of more ready-to-drink beverage products.

The impact of technology that allows ingredients in one country to be shipped efficiently to ports on the other side of the globe or allows information on the latest beverage flavor creation to be transmitted around the world in seconds has huge impacts and expands the beverage choices we have. Travel and immigration bring consumers closer to products that they never before had the opportunity to experience. Cultural shifts in every part of the world have modified consumers' needs and wants for beverages. This gives researchers and manufacturers unparalleled opportunities for study, innovation, and adaptation to changing lifestyles.

We regularly hear of new options in ingredients such as "functional" nutritional ingredients, technologies for packaging, manufacturing processes, marketing strategies, and new markets for existing products. These diverse innovations push developers, researchers, marketers, and policy makers to provide 
a diverse marketplace while holding down costs and creating positive evidence-based societal outcomes based on multiple criteria rather than a single minded socio-political bias.

Beverage options also are influenced by issues such as the scientific constraints on formulations, the practical impacts of manufacturing and packaging, the realities of marketing and promotion, and limits on availability. Regulatory boundaries also exist for beverages in areas such as ingredients (e.g., sweeteners), allowable market claims, public health promotional efforts (e.g., taxes), and environmental legislation (e.g., plastic containers).

Niche markets for beverages abound. Product segments based on sensory properties, health, age, emotional needs (e.g., relaxation or energy), and consumer movements (e.g., local products, natural, clean label) result in an enormous number of new beverage product creations each year. The development or modification of products that help consumers with specific health issues (e.g., nutritional beverages for diabetics, thickened liquids for dysphagia patients), specialized infant formulas, and weight loss or weight gain beverages, for example, have opened yet another door for the expansion of research on beverages.

The wide range of beverage products provides a means for researchers in all parts of the world to play a part in expanding our knowledge of beverage consumption, types of products, health and safety of beverages, and development and creation of new beverage products. The potential for research is boundless and this journal, Beverages, is intended to be a public open access repository of researchbased information on beverages.

(C) 2014 by the authors; licensee MDPI, Basel, Switzerland. This article is an open access article distributed under the terms and conditions of the Creative Commons Attribution license (http://creativecommons.org/licenses/by/4.0/). 